\title{
Investigation on the Tensile and Flexural Properties of Coir-fibre- reinforced Polypropylene Composites
}

\author{
K. Begum ${ }^{1}$, M. A. Islam ${ }^{2, *}$, M. M. Huque ${ }^{3}$ \\ ${ }^{1}$ Department of Physics, Shahjalal University of Science and Technology (SUST), Sylhet 3114, \\ Bangladesh \\ ${ }^{2}$ Department of Chemical Engineering and Polymer Science, Shahjalal University of Science \\ and Technology (SUST), Sylhet 3114, Bangladesh \\ ${ }^{3}$ Department of Chemistry, Bangladesh University of Engineering and Technology, Dhaka \\ 1000, Bangladesh
}

Received 23 April 2015, accepted in final revised form 30 May 2015

\begin{abstract}
The utilization of natural fibres as reinforcement in polymer composites has been increased significantly for their lightweight, low cost, high specific strength, modulus and biodegradable characteristic. In this present work, the mechanical properties of randomly distributed short coir-fibre-reinforced polypropylene (PP) composites have been studied as a function of fibre loading. In order to improve the composite's mechanical properties, raw coir fibres were treated with $1 \%$ alkali $(\mathrm{NaOH})$ solution. Both raw and alkali treated coir-fibre-reinforced PP composites were prepared with different fibre loadings $(10,15,20,25,30$ and $35 \mathrm{wt} \%)$ using a double roller open mixer machine and injection molding machine. The mechanical properties, such as tensile strength (TS), tensile modulus (TM), flexural strength (FS) and flexural modulus (FM) were investigated for the prepared composites. The alkali treated coir-fibre-reinforced PP composites showed better results in mechanical properties compared to untreated composites. Finally, the optical microscopic studies were carried out on fractured surfaces of the tensile test specimens, which indicated weak interfacial bonding between the fibre and the polymer.
\end{abstract}

Keywords: Coir fibres; Short-fibre polymer composite; Mechanical properties; Interfacial bonding.

(C) 2015 JSR Publications. ISSN: 2070-0237 (Print); 2070-0245 (Online). All rights reserved. doi: http://dx.doi.org/10.3329/jsr.v7i3.23075

J. Sci. Res. 7 (3), 97-111 (2015)

\section{Introduction}

Because of increasing environmental consciousness, over the last few decades researchers have been looking for the environment-friendly materials and the

*Corresponding author: mislam@sust.edu, islamsust@yahoo.com 
alternative to synthetic fibre reinforced polymer composites. In recent years, natural fibre-reinforced polymer composites (NFRPCs) have attracted the attention of the research community worldwide [1-7]; as because they have already been proven to be the alternatives to the conventional non-renewable and non-biodegradable materials, such as glass, carbon, kevlar, aramid etc. reinforced composites in various engineering applications. Natural fibres exhibit many advantageous properties which promote the replacement of synthetic fibres in polymer composites. They are low cost materials, easily available as a renewable resource, easily obtained, and as low-density material, yield relatively lightweight composites with high specific properties, and therefore natural fibres offer a high potential for an outstanding reinforcement in lightweight structures. Moreover, they are biodegradable and recyclable in nature. Pollutant gas emissions to the environment from natural fibre production are significantly lower than that from the synthetic fibre [3].

The use of natural fibres in composite materials, however, presents a few drawbacks due to some characteristics of the fibres such as quality variations, high moisture uptake, poor compatibility with hydrophobic polymer matrix and low thermal stability [4-7]. Natural fibres are hydrophilic in nature as they are derived from lignocellulose, which contain hydroxyl groups. These fibres, therefore, are inherently incompatible with hydrophobic thermoplastic matrix. The major limitations of using these fibres as reinforcements in such matrices include poor interfacial bonding between polar-hydrophilic fibre and non-polar-hydrophobic matrix and causes deterioration of the mechanical properties. The high moisture sensitivity of such lingo-cellulosic fibre limits the use of natural fibre as reinforcement in composite materials. In order to overcome these drawbacks various treatments have been used to improve the fibre-matrix adhesion as well as the physical and mechanical properties of natural fibre reinforced polymer composites [8-12].

In recent years, natural fibre (banana, jute, flax, hemp, sisal, abaca etc.) reinforced composite materials have been used in low-cost housing, and other civil structures as test cases [13-15], and scientists and technologists have been incessantly conducting experimentations on the improvement of the mechanical properties of the composites. Coir is also a natural fibre and is available in abundance in many countries. Because of its hard wearing quality, durability and other advantages, it is used for making products such as building boards, roofing sheets, insulation boards, building panels, as a lightweight aggregate, geo-textile, wide variety floor furnishing mats, doormats, brushes, mattresses, etc. in a wide range. But only a small percentage of the total annual production of coir fibres is being used for these purposes. Apart from these traditional uses of coir fibres, research and development efforts to utilize this fibre as reinforcement in polymer composites are scarce [16-17].

Coir is an important ligno-cellulosic fibre obtained from coconut fruit. But unfortunately, the performance of coir fibre as a reinforcement in polymer composites is unsatisfactory and not comparable even with the other natural fibres, which is attributed to low cellulose content and considerably high micro-fibrillar angle [18]. 
Wambua et al. [19] made a thorough analysis of perspective of the replacement of glass fibre by natural fibres and drew some pessimistic conclusion regarding the prospect of coir fibre as reinforcement material. The conclusion drawn by the authors, may be, has got some ground, but it is too early to make such a pessimistic statement before the mechanical strength being tested for a good number of polymer-coir composites. Furthermore, the improvement in the tensile strength (TS) could not be the only criterion for the judgment of the improvement of mechanical strength of some material. There are other parameters such as flexural strength (FS) for the evaluation of the mechanical strength as well. Also, keeping in mind the hard wearing quality and durability and also biodegradable nature of the coir fibre, the composite based on it could be used successfully as non-structural applications. In fact, few studies on coirfibre-reinforced polymer composites are available in literature as compared to those with other natural fibres. Thermoset polymers such as tannin-phenolic polymer [20] and epoxy resin [21] have showed good interfacial adhesion to the coir fibre and the corresponding composites show improvement in the mechanical properties. Geethamma et al. [22] reported that the alkali treatment could strengthen the interfacial adhesion between coir and natural rubber, but still coir-reinforced rubber showed decreasing TS with an increase in the fibre-load.

Among the thermoplastics used in the polymer-coir fibre composites, reports are available (as per the present survey) about the high impact polystyrene (HIPS) [23], high density polyethylene (HDPE) [24], starch/ethylene vinyl alcohol copolymers (EVOH) blends [25], polyester [26-28] and polypropylene (PP) [29-34]. Most studied polymer appeared to be PP in this respect.

Morandim-Giannetti et al. [35] showed that lignin has negative impact on adhesion and tensile properties and it was recommended that the fibre would be cleaned of lignin before being incorporated in the polymer composition. Usually treated fibres show better adhesion to polymers and yield better tensile properties to the PP composites than the untreated ones do. Different chemicals such as $o$ hydroxybenzene diazonium salt [30-31], basic chromium sulfate and sodium bicarbonate salt [33] and $\mathrm{NaOH}[29,34]$ have been used as treatment agents to improve the PP-coir fibre adhesion.

The observations on the effect of fibre-load on the mechanical properties vary from matrix to matrix. Even for a given polymer-coir fibre composite, observations by different authors are different. For HIPS-coir fibre composites Kelly et al. [23] observe no significant increment in the values of TS with increase in the fibre-load. Nam et al. [36] reported that for poly(butylene succinate)-coir fibre composites the TS passes through maximum for an increase in the fibre-load. Monteiro et al. [28] and Santafe et al. [27] found that the FS of coir fibre-polyester decreased with fibreloading. Rout et al. [26], on the other hand, reported that both the TS and FS for the coir fibre-polyester increased with fibre-loading.

For PP-coir fibre composites, most of the authors [30-31,34] showed that within the range of fibre-load under investigation, the TS shows a decreasing trend, but the 
FS as well as the tensile and flexural moduli (TM and FM) increase with an increase in the fibre loading.

There is something interesting to note in almost all the reports about the TS vs. fibre-load relationship for PP-coir fibre composites. As seen in the reports, the TS vs. fibre-load plot distinctly shows a decreasing trend, but the initial value i.e. the TS at the lowest fibre-load under investigation is usually higher than that of the pure polymer [30-31,33]. Such observation provides some 'evidence' in favor of the improvement in TS at low fibre-load. Unfortunately adequate data in the low fibreload range is missing in the literature to draw any categorical conclusion in favor of the improvement.

In this work, PP-coir fibre composites had been prepared with treated and untreated fibres, and the tensile and flexural properties had been investigated. A categorical answer was sought to the question 'Is there any improvement in TS in any range of fibre-loading, or the fibre simply deteriorates the property as compared to the pure polymer? Elaborate discussion was made on the mechanical properties achieved by previous authors for the similar composite systems. Morphology of the fractured surface had been investigated in order to get information about the fibre-polymer interfacial bonds and to explain the apparent deterioration of TS beyond a certain fibre-inclusion limit.

\section{Experimental}

\subsection{Materials}

The thermoplastic polymer, polypropylene (PP) (with the density of $881.8 \mathrm{~kg} / \mathrm{m}^{3}$ and a melt flow index of $15.5 \mathrm{~g} / 10 \mathrm{~min}$ measured at $230^{\circ} \mathrm{C}$ and $2.16 \mathrm{~kg}$ ) was collected from local market and was selected as the polymer matrix. Coir fibres used as reinforcement in composites were also collected from the local market. The fibres were chopped to make short fibres manually (roughly 2-8 mm).

\subsubsection{Treatment of coir fibres}

The coir fibres were first soaked in a hot detergent solution at $70^{\circ} \mathrm{C}$ for $30 \mathrm{~min}$ and washed several times with tap water and finally by distilled water. The washed fibres were then dried in open air for five days and subsequently in an electric oven at $105^{\circ} \mathrm{C}$ for $2 \mathrm{~h}$. These detergent-washed fibres were termed 'Raw fibres' in this work.

The raw fibres (detergent-washed) thus obtained were treated in a $1 \%$ alkali solution $(\mathrm{NaOH})$ at $70^{\circ} \mathrm{C}$ for $30 \mathrm{~min}$, then the fibres were washed several times with tap water and finally by distilled water to obtain alkali treated fibres. The washed fibres were then dried in open air for five days and subsequently in an electric oven at $105^{\circ} \mathrm{C}$ for $2 \mathrm{~h}$. 


\subsubsection{Preparation of composites and testing of mechanical properties}

The blending/melt mixing of the coir fibres and PP were carried out at $142^{\circ} \mathrm{C}$ using a double roller open mixer machine (Product of Dong Guang LiNa Machinery Industrial Co., LTD). PP composites were prepared with 'raw' and treated fibres. The coir fibres content varied from 10 to $35 \%$ by weight of the composites. The prepared composites were then dried in open air and cut into small pieces manually to make them suitable for loading inside the barrel of the injection molding machine. Bone-shaped specimens were prepared for tensile test and rectangular shaped specimens were prepared for flexural tests.

Tensile tests (TS and TM) of bone-shaped composite specimens were carried out using Universal Testing Machine (UTM, Model H $10 \mathrm{~K}-\mathrm{S}$ ) supplied by Hounsfield Equipment, USA, at a load range of $2000 \mathrm{~N}$, crosshead speed, of $5 \mathrm{~mm} / \mathrm{min}$. To minimize the experimental error five specimens of each kind of material were tested.

The three-point flexural tests (FS and FM) were performed using Universal Testing Machine (UTM, Model H 10 K-S) supplied by Hounsfield Equipment, USA. A load range of $2000 \mathrm{~N}$, crosshead speed, of $2 \mathrm{~mm} / \mathrm{min}$, was chosen according to ASTM standard D790-00 for flexural properties of unreinforced and reinforced plastic materials. Five specimens for each material were tested.

\subsubsection{Optical spectroscopy}

Optical spectroscopic image of the fractured surface at tensile test of the samples were recorded using Stereo Zoom Microscope, (CZM6 Trinocular Microscope 4123200, magnification 5x) supplied by LABO AMERICA, INC, U.S.A.

\subsubsection{FTIR spectra}

The infrared spectra of the raw coir fibre and alkali treated coir fibre were recorded as $\mathrm{KBr}$ pellets by IR spectrophotometer (SHIMADZU, dxp-400).

\section{Results and Discussions}

\subsection{Effect of fibre content and chemical treatment on tensile properties}

\subsubsection{Tensile strength (TS)}

Fig. 1 shows the effect of both untreated (raw) and treated coir fibre content on the TS of the coir-fibre-PP composite. The TS of the virgin PP is $28 \mathrm{MPa}$. The fibre content was varied from 10 to $35 \mathrm{wt} \%$ to investigate on the effect of fibre content on mechanical properties. The results show that in the low fibre-loading range there is a slight decrease (insignificant decreasing trend) in TS as compared to that of the pure 
PP. With the increase of fibre content from 10 to $25 \mathrm{wt} \%$ the TS increases for both the raw and alkali treated coir-fibre PP composites, but beyond that fibre content limit, the TS decreases. Such deterioration of the TS with a fibre-load higher than $25 \%$ is much more pronounced in case of untreated fibre-PP composites, which exibits a much lower TS at 35 wt\% fibre-content than the pure PP. The inherent hydrophilic nature of coir fibre weakens the interfacial bonding between hydrophobic PP and hydrophilic coir fibre and causes deterioration of the mechanical properties. In order to improve the fibre-matrix adhesion and ultimately to achieve better mechanical properties of the composites, the coir fibres were chemically treated by alkali treatment in the present study. It is observed from the Fig. 1 that the TS of the composites reinforced by chemically treated coir fibres increases at all fibre loadings as compared to the raw fibre-PP composites. In treated fibre-PP composites, the TS increases (approximately $10 \%$ ) with an increase of fibre loading up to $25 \mathrm{wt} \%$ and then decreases to a minimum value at $35 \mathrm{wt} \%$ fibre loading. Definitely, the alkali treatment provides better adhesion between the components and hence higher strength. The ultimate change of the TS achieved by the alkali treatment of the fibre may be attributed to the net effect of the change in the structure of the cellulose unit of coir as well as to the simple removal of lignin and hemicelulose components of fibres during alkali treatment. The alkali treatment of coir fibres reduces the hydrophilic groups of the cellulose unit.

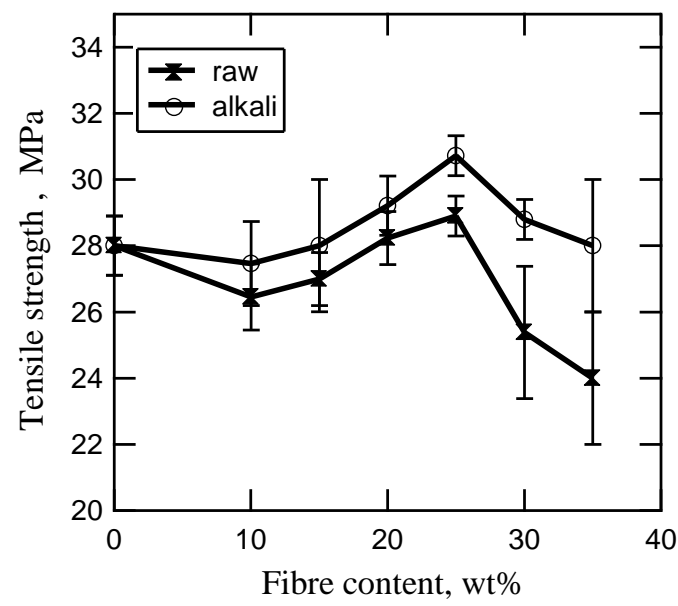

Fig. 1. Variation of tensile strength (TS) of PP composites reinforced with raw and alkali $(\mathrm{NaOH})$ treated coir fibre.

With a view to finding evidence of changes in the chemical structure of the fibre due to alkali treatment, that ultimately leads to better adhesion between the components, a FTIR spectroscopic analysis has been made on both the untreated and treated coir fibre (Fig. 2). In comparison with the untreated fibre, the alkali treated fibre shows a reduction in O-H stretching intensity and shifting of the peak from $\sim 3430 \mathrm{~cm}^{-1}$ to $\sim 3354 \mathrm{~cm}^{-1}$, indicating participation of some free hydroxyl groups of 
cellulose and lignin components in these chemical reactions. It is clear in the spectrum of the untreated coir fibre that a strong and sharp absorption band $\sim 1736 \mathrm{~cm}^{-1}$ corresponding to the carbonyl $(\mathrm{C}=\mathrm{O})$ stretching of the acetyl groups of hemi-cellulose [37] and aldehyde groups in lignin [38] visible in untreated coir fibres disappear in alkali-treated fibre. The similar observations were also made by other researchers $[8,24,32,39-42]$. The disappearance of these characteristic peaks clearly indicated that the hemicellulose and lignin contents on fibre surface are significantly removed due to alkali treatment. Thus, it is beyond doubt that the alkali treatment reduces the hydrophilic nature of coir fibre responsible for moisture absorption and enhances its hydrophobic nature. The PP itself being of hydrophobic nature has better compatibility with fibres with lowered hydrophilicity. Consequently, better interfacial adhesion between the treated coir fibre and PP matrix is achieved upon chemical treatment, leading to the improved mechanical properties of the composites.

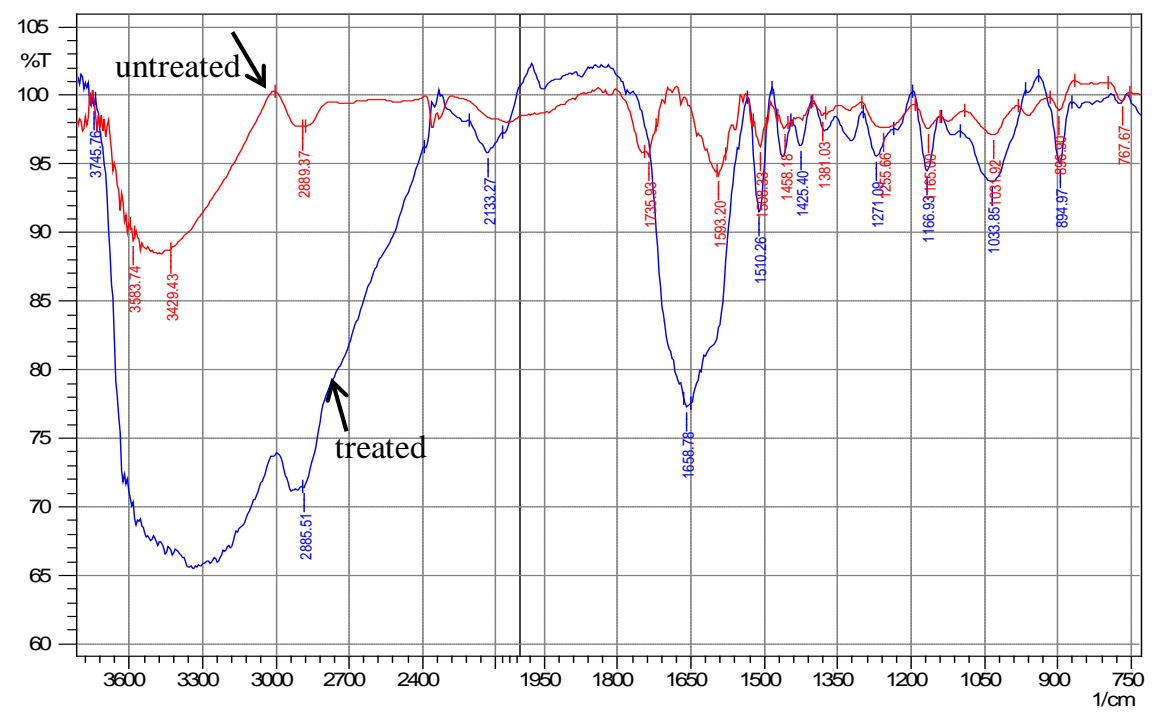

Fig. 2. FTIR spectra of untreated and alkali $(\mathrm{NaOH})$ treated coir fibre.

The TS results obtained by alkali treated coir-fibre PP composites in the present study are compared with previous observations available in literature. In previous record, studies were carried out on coir fibre-PP composites [31,33,34] Islam et al. [31] have investigated the physico-mechanical properties of $10-25 \mathrm{wt} \%$ raw and $o$ hydroxybenzene diazonium salt-treated coir reinforced PP composites. As they claim, although no increment in TS is found for untreated coir-PP composites, the values of $o$-hydroxybenzene diazonium salt-treated coir-PP composites at all mixing ratios are higher (improvement, 3.7-11\%) than that of the neat PP. Arrakhiz et al. [34] find no increment in the TS for alkali treated coir PP composites. They find that the TS monotonously decreases as the fibre-load increases. Similar to Arrakhiz et al., Mir et al. [33] also find the same trend of the change of TS as a function of fibre load, except 
a little bit increment (5\%) at $10 \mathrm{wt} \%$ fibre composite. Therefore, it can be concluded, that no particular trend of the change of TS with the fibre content is observed by previous authors. In some cases the TS decreases with the increase of fibre content, in other cases increases or shows anomalous behavior. In the present study, a fibre load range (15-35 wt\%) is found, where the TS is higher than the pure PP.

\subsubsection{Tensile modulus (TM)}

The variation of TM of the PP composites reinforced by untreated and treated coir fibres with fibre content (wt\%) is presented in Fig. 3. The TM of the reference PP is $542 \mathrm{MPa}$. From the Fig. it is observed that for both the untreated and alkali treated fibre composites TM is, somewhat, increasing linearly with the increase in fibre content which is consistent with other previous research [8,23,32,43-45]. This is because coir fibre has higher modulus than pure $\mathrm{PP}$, and the incorporation of the fibre into the pure polymer matrix has improved the stiffness of the composites [31,34]. As observed by the present research, the TM increased from $770 \mathrm{MPa}$ at $10 \mathrm{wt} \%$ fibre content to $1086 \mathrm{MPa}$ at $35 \mathrm{wt} \%$ fibre content for alkali treated coir-fibre composites. However, due to the effect of alkali, maximum 100\% TM are observed by $35 \mathrm{wt} \%$ fibre in comparison with pure PP. The increment of TM found in the present work (86\%) is higher than those obtained by Arrakhiz et al. [34] (56\%), but still very much lower than those obtained by Islam et al. [31] (269\%) using the same fibre material during the fibre load range of $0-25 \mathrm{wt} \%$.

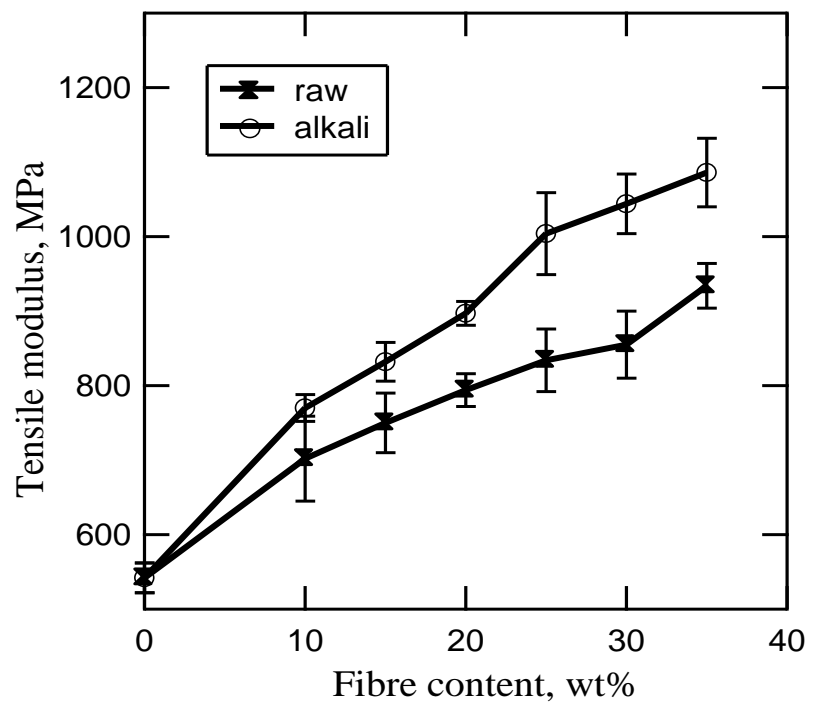

Fig. 3. Variation of tensile modulus (TM) of PP composites reinforced with raw and alkali $(\mathrm{NaOH})$ treated coir fibre. 


\subsection{Percentage elongation at break}

Elongation at break of PP composites reinforced by raw and alkali treated coir fibre as a function of fibre content (wt\%) is presented in Fig. 4. As observed in the Fig., the alkali treated coir fibre composites showed relatively greater elongation at break for all compositions. This is due to improved interfacial bonding between fibre and matrix and it implies that the ductility of the alkali-treated coir composites has been increased. However, for both systems (raw and alkali treated fibre composites) a decreasing trend in elongation at break has been demonstrated with the increase of fibre loading. This phenomenon is observed because the addition of stiff fibre interrupted the PP segment mobility and thus turning the plastic to be more brittle.

Reviewing the previous literature [23,26-27,45-47], it can be said that no regular trend of the variation of elongation at break with fibre content is observed. The increase of fibre loading affects the elongation at break of different composites differently - in some cases increases, in other cases decreases or shows anomalous behavior. For example, Santafe et al., Portela et al. and Uma Devi et al., [27,45-46] showed that the variation of elongation at break with fibre content is anomalous. On the other hand, Carvalho et al. [23] and Chollakup et al. [47] showed the decreasing behavior of elongation at break with fibre content and the trend is similar to that observed in the present study. Unlike Carvalho et al. [23] and Chollakup et al. [47], Rout et al. [26] showed that the elongation at break for coir-fibre polyester composites increased with the increase of fibre content.

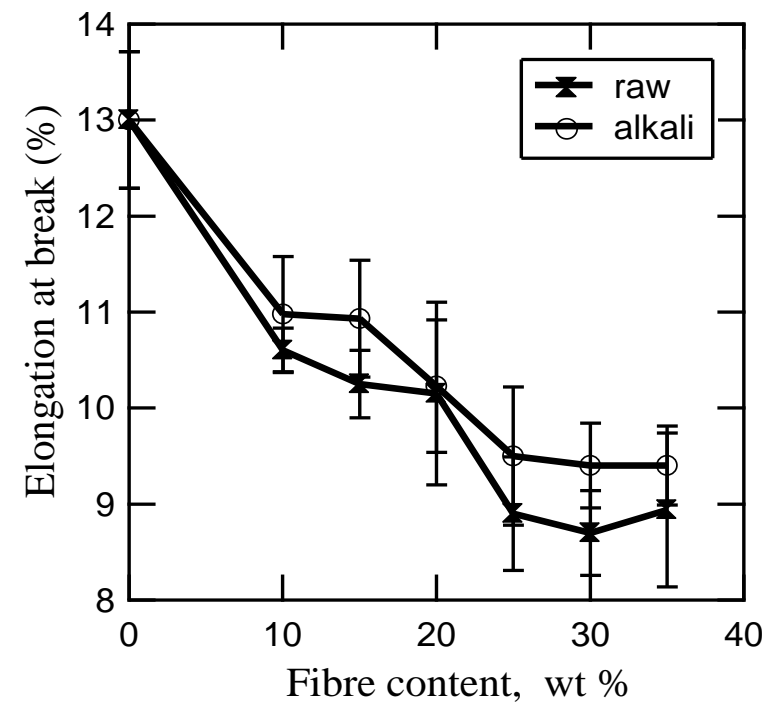

Fig. 4. Elongation at break vs. fibre content plot for raw and alkali $(\mathrm{NaOH})$ treated coir fibre reinforced PP composites. 


\subsection{Effect of fibre content and chemical treatment on flexural properties}

\subsubsection{Flexural strength (FS)}

Fig. 5 shows the variation of FS of unreinforced PP and its raw coir fibre and alkali treated coir fibre reinforced composites as a function of fibre loading (wt\%). The FS of the reference PP is $35 \mathrm{MPa}$. Fig. 5 indicates that for both raw and alkali treated coir fibre reinforced composites, the addition of fibres increased the FS of the composites as compared to unreinforced PP. It is also seen from the Fig. that for the raw and alkali treated coir fibre reinforced PP composites, maximum FS values were found to be 56 MPa and $62 \mathrm{MPa}$ at $10 \mathrm{wt} \%$ and $15 \mathrm{wt} \%$ fibre loading, which are respectively $60 \%$ and $77.14 \%$ higher than the pure PP. The Fig. also shows that beyond a certain fibreload limit, there is a decreasing trend of the FS. Between the two systems, the FS value for alkali treated fibre composites is higher. The enhancement in the FS in alkali treated fibre composites is attributed to the improved wetting of alkali treated coir fibre with $\mathrm{PP}$. NaOH-treatment is mainly a process of surface activation. It leads to the formation of rough fibre surface, which would increase the mechanical interlocking between the fibre and PP matrix [26].

The result obtained in terms of FS in the present study is higher than those reported in literature for the similar systems. For example, Islam et al. [31] reported that the FS suddenly increased from $43.50 \mathrm{MPa}$ at $0 \mathrm{wt} \%$ to $55.65 \mathrm{MPa}$ at $10 \mathrm{wt} \%$ (27.94\% increment) and the value remained almost constant up to $25 \mathrm{wt} \%$ fibre. Mir et al. [33] and Arrakhiz et al. [34] found that the FS increased linearly with the fibre content for coir-fibre PP composites and achieved $75.76 \%$ and $20.52 \%$ increment (at $20 \mathrm{wt} \%$ fibre loading) compared to pure PP. Thus, no pessimistic conclusion could be drawn yet regarding the mechanical strength of the composite. Definitely, the material deserves further studies and efforts to unravel its potentiality.

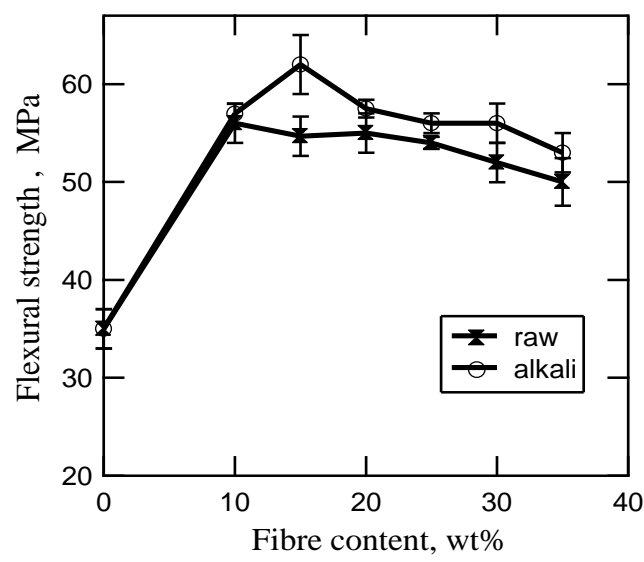

Fig. 5. Variation of flexural strength (FS) of PP composites reinforced with raw and alkali $(\mathrm{NaOH})$ treated coir fibre. 


\subsubsection{Flexural modulus (FM)}

The variation of FM of PP composites reinforced by raw and alkali treated coir fibres as a function of fibre content (0-35 wt\%) is illustrated in Fig. 6. The FM of the reference PP is $960 \mathrm{MPa}$. From the Fig., it is observed that for all composite systems FM increased gradually with the increase in fibre content from 0 to $35 \mathrm{wt} \%$. For raw fibre composites FM increased from $960 \mathrm{MPa}$ for pure PP to $2543 \mathrm{MPa}$ for $35 \mathrm{wt} \%$ fibre loading. Therefore, the reinforcement of $35 \mathrm{wt} \%$ raw fibre has obviously increased the FM of pure PP as much as $165 \%$. On the other hand, in the case of alkali treated composite, maximum FM value was found to be $3207 \mathrm{MPa}$ at $35 \mathrm{wt} \%$ fibre loading, which is $234 \%$ higher than the unreinforced PP. Thus, the alkali treated fibre reinforced composites showed the superior FM results and 69\% higher FM has been achieved over the raw fibre composites. Similar results were also reported in the previous literature for coir-fibre PP and also for different composites [29,31,33$34,36,46,48-49]$.

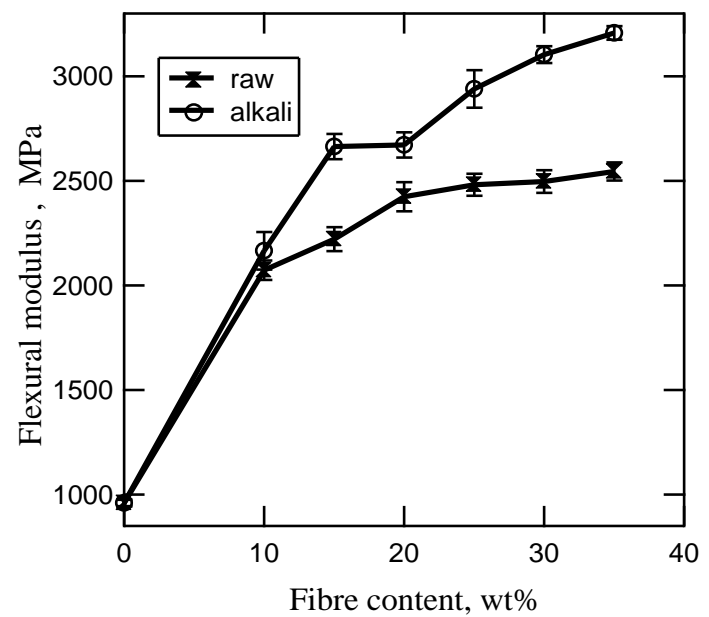

Fig. 6. Variation of flexural modulus (FM) of PP composites reinforced with raw and alkali $(\mathrm{NaOH})$ treated coir fibre.

\subsection{Morphology of fractured surface}

The morphology of the fractured surfaces reveals the variation of mechanical properties of composites prepared from fibres of different surface properties. The optical microscopic images of the fractured surfaces of $25 \mathrm{wt} \%$ untreated and alkali treated coir fibre reinforced PP composite after tensile test have been shown in Figs. 7(a-b). From the Figs. it is clearly seen that the fibres are wiping out from its place of polymer matrix, indicating the poor interfacial adhesion between fibre and polymer matrix. The weak adhesion between fibre-matrix interface leads to the lower TS for both untreated and treated fibre composites. However, less number of fibres are found 
to be pulled out from alkali treated fibre composite (Fig. 7b), indicating that better fibre-matrix interactions has been obtained upon chemical treatment of fibre and the composite showed better TS than the untreated one.
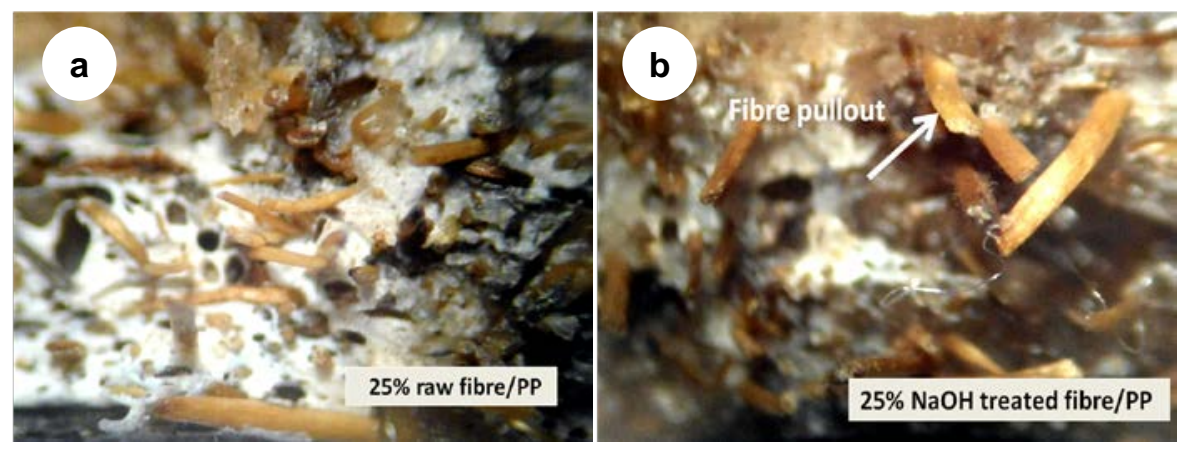

Fig. 7. Optical microscopic images of the fractured surface after tensile test of (a) $25 \mathrm{wt} \% \mathrm{raw}$ coir-fibre-reinforced PP composites and (b) $25 \mathrm{wt} \%$ alkali treated coir-fibre-reinforced PP composites

\section{Conclusion}

From the experimental results the following conclusions can be drawn:

1. Randomly oriented short coir fibres (untreated and treated) incorporated in PP matrix composites did not improve the TS, except for a slight increment, $10 \%$ increment over pure PP, due to weak interfacial bonding between fibres and matrix as confirmed by optical microscopic view.

2. Significant increment in TM is observed for both untreated and treated coir fibre reinforced PP composites. Alkali-treated coir fibre reinforced PP composites showed improved TM for all fibre content than the untreated one.

3. The alkali-treated coir fibre composites showed relatively greater elongation at break for all compositions compared to the untreated fibre composites i.e. the ductility of the alkali-treated coir composites has been increased. This is due to improved interfacial bonding between fibre and matrix.

4. Improved FS is observed for both untreated and treated coir fibre reinforced polymer composites. The optimum FS were observed at 10 and $15 \mathrm{wt} \%$ fibre contents for the raw and alkali treated coir fibre reinforced PP composites respectively and beyond that the strength vs. fibre content showed a decreasing trend. For untreated fibre reinforced composite, the FS is improved by $60 \%$ and for treated fibre composite this is improved by $77.14 \%$ over the pure PP. A useful composite with good FS could be successfully designed/developed using coir-fibres as a reinforcing agent for PP matrix for nonstructural applications.

5. Improved FM is observed for both untreated and treated coir fibre reinforced polymer composites. The FM increased gradually with the increase of fibre 
content for both untreated and treated composites. For treated fibre reinforced polymer composite $110 \%$ higher TM is observed than the untreated fibre reinforced polymer composite.

6. Optical microscopic images of the fractured surfaces of both untreated and alkali treated coir fibre reinforced PP composite after tensile test reveal the weak interfacial adhesion between fibre and matrix which causes the low TS of the composites.

\section{Acknowledgment}

The authors deeply acknowledge the financial support from the Ministry of Science and Technology, Bangladesh (Grant No.EAS-7/582/1(5)/2012) and the SUST (Shahjalal University of Science and Technology) Research Grant for carrying out this research. The author Khurshida Begum is also thankful to the Ministry of Science and Technology, Bangladesh for providing her the NST fellowship (Grant No. 363(105)/2011).

\section{References}

1. M. A. Islam and K. Begum, J. Sci. Res. 3(2), 225 (2011). http://dx.doi.org/10.3329/jsr.v3i2.6881

2. M. R. Hossain, M. F. Hossain, and M. A. Islam, J. Sci. Res. 6(3), 431 (2014). http://dx.doi.org/10.3329/jsr.v6i3.15811

3. B. C. Suddell and W. J. Evans, The Increasing Use and Application of Natural Fibre Composite Materials within the Automotive Industry. International Conference on Woodfibre-Plastic Composites (ICWFPC) (Forest Products Society, Madison, WI, 2003).

4. A. K. Bledzki, S. Reihmane, and J. Gassan, Polym. Plast. Technol. 37(4), 451 (1998). http://dx.doi.org/10.1080/03602559808001373

5. R. Rowell, A. R. Sanadi, D. F. Caulfield, and R. E. Jacobson, "Utilization of Natural Fibres in Plastic Composites: Problems and Opportunities" in Lignocellulosic-plastics composites, A. L. Leao, F. X. Carvalho, and E. Frollini (eds) (USP and UNESP, Brazil, 1997) pp. 23.

6. J. L. Lopez, M. Sain, and P. Cooper, J. Appl. Polym. Sci. 99, 2570 (2006). http://dx.doi.org/10.1002/app.22884

7. A. Bessadok, S. Roudesli, S. Marais, N. Follain, and L. Lebrun, Composites: Part A. 40(2), 184 (2009). http://dx.doi.org/10.1016/j.compositesa.2008.10.018

8. S. K. Chattopadhyay, R. K. Khandal, R. Uppaluri, and A. K. Ghoshal, J. Appl. Polym. Sci. 117, 1731 (2010).

9. A. K. Bledzki, A. A. Mamun, A. Jaszkiewicz, and K. Erdmann, Compos. Sci. Technol. 70, 854 (2010). http://dx.doi.org/10.1016/j.compscitech.2010.02.003

10. S. K. Chattopadhyay, R. K. Khandal, R. Uppaluri, and A. K. Ghoshal, J. Appl. Polym. Sci. 119, 1619 (2011). http://dx.doi.org/10.1002/app.32826

11. A. K. Bledzki, A. A. Mamun, M. Lucka-Gabor, and V. S. Gutowski, Express. Polym. Lett. 2(6), 413 (2008). http://dx.doi.org/10.3144/expresspolymlett.2008.50

12. K. Joseph, S. Thomas, and C. Pavithran, Polymer 37(23), 5139 (1996). http://dx.doi.org/10.1016/0032-3861(96)00144-9

13. N. S. M. El-Taybe, Mater. Design. 30, 1151 (2009). http://dx.doi.org/10.1016/j.matdes.2008.06.024 
14. N. G. Justiz-Smith, G. J. Virgo, and V. E. Buchanan, Mater. Charact. 59(9), 1273 (2008). http://dx.doi.org/10.1016/j.matchar.2007.10.011

15. M. A. S. Spinace, C. S. Lambert, K. K. G. Fermoselli, and M. A. De Paoli, Carbohydr. Polym. 77(1), 47 (2009). http://dx.doi.org/10.1016/j.carbpol.2008.12.005

16. C. Pavithran, P. S. Mukherjee, and M. Brahmakumar, J. Reinf. Plast. Comp. 10, 91 (1991). http://dx.doi.org/10.1177/073168449101000106

17. N. Arumugam, K. Tamareselvy, K. Venkata Rao, and P. Rajalingam, J. Appl. Polym. Sci. 37, 2645 (1989). http://dx.doi.org/10.1002/app.1989.070370916

18. A. K. Mohanty, M. Misra, and G. Hinrichsen, Macromol. Mater. Eng. 276/277, 1 (2000). http://dx.doi.org/10.1002/(SICI)1439-2054(20000301)276:1<1::AID-MAME1>3.0.CO;2-W

19. P. Wambua, J. Ivens, and I. Verpoest, Compos. Sci. Technol. 63, 1259 (2003). http://dx.doi.org/10.1016/S0266-3538(03)00096-4

20. J. V. Barbosa, E. C. Ramires, I. A. T. Razera, and E. Frollini, Ind. Crop. Prod. 32, 305 (2010). http://dx.doi.org/10.1016/j.indcrop.2010.05.007

21. F. I. Romli, A. N. Alias, A. S. M. Rafie, and D. L. A. A. Majid, AASRI Procedia. 3, 242 (2012). http://dx.doi.org/10.1016/j.aasri.2012.11.040

22. V. G. Geethamma, K. T. Mathew, R. Lakshminarayanan, and S. Thomas, Polymer 39(6-7), 1483 (1998). http://dx.doi.org/10.1016/S0032-3861(97)00422-9

23. K. C. C. Carvalho, D. R. Mulinari, H. J. C. Voorwald, and O.H. Maria, BioRresources. 5(2), 1143 (2010).

24. F. Z. Arrakhiz, M. El Achaby, A. C. Kakou, S. Vaudreuil, K. Benmoussa, R. Bouhfid, O. Fassi-Fehri, and A. Qaiss, Mater. Design. 37, 379 (2012). http://dx.doi.org/10.1016/j.matdes.2012.01.020

25. M. F. Rosa, B. Chiou, E. S. Medeiros, D. F. Wood, T. G. Williams, L. H. C. Mattoso. W. J. Orts. S. H. Imam, Bioresource Technol. 100(21), 5196 (2009). http://dx.doi.org/10.1016/j.biortech.2009.03.085

26. J. Rout, M. Misra, S. S. Tripathy, S. K. Nayak, and A. K. Mohanty, J. Polym. Compos. 22(4), 468 (2001). http://dx.doi.org/10.1002/pc.10552

27. H. P. G. Santafé Júnior, F. P. D. Lopes, L. L. Costa, and S. N. Monteiro, Rev. Mat. 15(2), 113 (2010).

28. S. N. Monteiro, L. A. H. Terrones, and J. R. M. D’Almeida, Polym. Test 27(5), 591 (2008). http://dx.doi.org/10.1016/j.polymertesting.2008.03.003

29. H. Gu, Mater. Design 30(9), 3931 (2009). http://dx.doi.org/10.1016/j.matdes.2009.01.035

30. M. M. Haque, M. Hasan, M. S. Islam, M. E. Ali, Bioresource Technol. 100(20), 4903 (2009). http://dx.doi.org/10.1016/j.biortech.2009.04.072

31. M. N. Islam, M. R. Rahman, M. M. Haque, and M. M. Huque, Compos. Part A: Appl. S. 41(2), 192 (2010).

32. P. Sudhakara, D. Jagadeesh, Y. Wang, C. V. Prasad, A. P. K. Devi, G. Balakrishnan, B. S. Kim, and J. I. Song, Carbohydr. Polym. 98(1), 1002 (2013).

http://dx.doi.org/10.1016/j.carbpol.2013.06.080

33. S. S. Mir, N. Nafsin, M. Hasan, N. Hasan, and A. Hassan, Mater. Design 52, 251 (2013). http://dx.doi.org/10.1016/j.matdes.2013.05.062

34. F. Z. Arrakhiz, M. Malha, R. Bouhfid, K. Benmoussa, and A. Qaiss, Compos. Part B-Eng. 47, 35 (2013). http://dx.doi.org/10.1016/j.compositesb.2012.10.046

35. A. A. Morandim-Giannetti, J. A. M. Agnelli, B. Z. Lanças, R. Magnabosco, S. A. Casarin, S. H. P. Bettini, Carbohydr. Polym. 87(4), 2563 (2012). http://dx.doi.org/10.1016/j.carbpol.2011.11.041

36. T. H. Nam, S. Ogihara, N. H. Tung, and S. Kobayashi, Compos. Part B-Eng. 42(6), 1648 (2011). http://dx.doi.org/10.1016/j.compositesb.2011.04.001

37. K. G. Satyanaryana, K. Sukumaran, P. S. Mukherjee, C. Pavithran, and S. G. K. Pillai, Cem. Concr. Compos. 12(2), 117 (1990). http://dx.doi.org/10.1016/0958-9465(90)90049-4

38. L. M. Matuana, J. J. Balatinecz, R. N. S. Sodhi, C. B. Park, Wood. Sci. Technol. 35(3), 191 (2001). http://dx.doi.org/10.1007/s002260100097 
39. U. Hujuri, S. K. Chattopadhay, R. Uppaluri, and A. K. Ghoshal, J. Appl. Polym. Sci. 107, 1507 (2008). http://dx.doi.org/10.1002/app.27156

40. S. K. Chattopadhyay, R. K. Khandal, U. Ramagopal, and A. K. Ghoshal, J. Appl. Polym. Sci. 117, 1731 (2010).

41. P. J. Herrera-Franco and A. Valadez-Gonzalez, Compos. Part B-Eng. 36, 597 (2005). http://dx.doi.org/10.1016/j.compositesb.2005.04.001

42. X. Y. Liu and G. C. Dai, Express. Polym. Lett. 1, 299 (2007). http://dx.doi.org/10.3144/expresspolymlett.2007.43

43. S. K. Chattopadhay, R. K. Khandal, R. Uppaluri, A. K. Ghoshal, J. Appl. Polym. Sci. 119, 1619 (2011). http://dx.doi.org/10.1002/app.32826

44. P. J. Roe and M. P. Ansell, J. Mate. Sci. 20, 4015 (1985).

45. T. G. R. Portela, L. L. da Costa, N. S. S. Santos, F. P. D. Lopes, and S. N. Monteiro, Rev. Mat. 15(2), 216 (2010).

46. L. Uma Devi, S. Bhagawan, and S. Thomas, J. Appl. Polym. Sci. 64, 1739 (1997). http://dx.doi.org/10.1002/(SICI)1097-4628(19970531)64:9<1739::AID-APP10>3.0.CO;2-T

47. R. Chollakup, R. Tantatherdtam, S. Ujjin, and K. Sriroth, J. Appl. Polym. Sci. 119, 1952 (2011). http://dx.doi.org/10.1002/app.32910

48. S. Shibata, Y. Cao, and I. Fukumoto, J. Appl. Polym. Sci. 100, 911 (2006). http://dx.doi.org/10.1002/app.22609

49. A. K. Rana, A. Mandal, B. C. Mitra, R. Jacobson, R. Rowell, and A. N. Banerjee, J. Appl. Polym. Sci. 69, 329 (1998). http://dx.doi.org/10.1002/(SICI)10974628(19980711)69:2<329::AID-APP14>3.0.CO;2-R 